\title{
Hippocampectomy attenuates the reduction of operant rate produced by d-amphetamine
}

\author{
MICHAEL L. WOODRUFF \\ Department of Anatomy and Department of Psychiatry and Behavioral Sciences \\ College of Medicine, East Tennessee State University, Johnson City, Tennessee 37614
}

\begin{abstract}
Hippocampal ablations in rats were found to significantly attenuate the response-decreasing effect of d-amphetamine observed when control animals perform on the fixed ratio (FR) component of a multiple FR, extinction (EXT) schedule under the drug's influence but had no effect on the ability of the drug to facilitate responding on the EXT component. Separate experiments indicated that hippocampal ablation neither increased nor decreased the ability of amphetamine to produce anorexia, stereotypy, or increases in locomotion. The data from these experiments are interpreted to indicate that the hippocampus is one structure involved specifically in the ability of amphetamine to lower response rate on an FR schedule and that the hippocampus may be part of the neural substrate of the phenomenon of "rate dependency," which is one predictor of the behavioral action of amphetamine. These data may be interpreted within a theoretical framework that ascribes to the hippocampus a function in altering behavior when either the internal or the external environment changes.
\end{abstract}

Behavioral responses to amphetamine are altered following destruction of various brain regions. For example, lesions of the corpus striatum (Neil, Boggan, \& Grossman, 1974) or of the substantia nigra (Iversen, 1974) reduce or even eliminate amphetamine-induced stereotypy. In addition, frontal neocortical lesions have been reported to enhance amphetamine-induced increments in locomotor activity in rats (Adler, 1961), mice (Glick, 1972), and monkeys (Miller, 1976). Although the effect of frontal lesions on amphetamineinduced increases in activity may decline over time (Lynch, Ballantine, \& Campbell, 1969), a more enduring facilitation of the effect of amphetamine on locomotion has been reported to follow hippocampal destruction in rats (Campbell, Ballantine, \& Lynch, 1971). Moreover both frontal neocortical and hippocampal lesions have been reported to alter the influence of amphetamine on operant responding. For example, Glick and Marsanico (1974) found that ablation of frontal neocortex in rats enhanced the facilitatory effects of low doses of d-amphetamine $(.25-.5 \mathrm{mg} / \mathrm{kg})$ on performance under a fixed interval (FI) 15-sec schedule of water reinforcement but decreased the depressant effects of higher doses (2.0$4.0 \mathrm{mg} / \mathrm{kg}$ ) on the same schedule.

Hippocampal lesions may have a more unitary effect on the alteration produced in operant performances by amphetamine. Woodruff and Isaacson (1977) reported that hippocampal ablations reduced

This research was supported in part by Biomedical Research Development Grant 1-508-RR09171-02. I am pleased to acknowledge the helpful comments of R. H. Baisden, H. E. Criswell, and R. G. Skalko concerning initial versions of this paper and the assistance of Donna Hammond in preparation of the manuscript. the decrement in performance on a fixed ratio (FR) 6 schedule of food reinforcement produced in rats in control groups by dl-amphetamine at dose levels of $.1, .5,1.0$, and $1.5 \mathrm{mg}$ of the salt per kilogram of rat body weight. However, unlike the effect of damphetamine on responding under the FI 15 schedule used by Glick and Marsanico, dl-amphetamine only lowered response rate in the control groups in the experiment by Woodruff and Isaacson. Whether or not hippocampal lesions might augment the effect of amphetamine on an operant schedule under which this drug facilitated response rate in normal rats has not been determined. Such consequences of hippocampal ablation might be predicted because of the similarities, noted above, between the effect of frontal neocortical ablation and hippocampal ablation on locomotor response to amphetamine.

\section{EXPERIMENT 1}

This experiment was conducted to determine whether hippocampal ablation would augment the facilitation of responding on some operant schedules produced by d-amphetamine in normal rats. Amphetamine is known to decrease high predrug response rates (Dews, 1958; Dews \& Wenger, 1977). Both high and low response rates can be generated within a single experiment by a single animal if an appropriate multiple schedule of reinforcement is employed. A multiple schedule of reinforcement consists of two or more independent schedules presented successively to a subject within the same test period. Each schedule is associated with a different exteroceptive stimulus (Ferster \& Skinner, 1957). In Experiment 1, an FR 32 schedule of food reinforce- 
ment, signaled by presentation of cue lights, was presented sequentially with an extinction component during which responding had no programmed consequence and the cue lights were not illuminated.

\section{Method}

Subjects and Surgical procedures. Thirty Long-Evans hooded rats weighing between 285 and $342 \mathrm{~g}$ at the beginning of the experiment were used. They were housed individually, and water was available in the home cage throughout the experiment. A 14:10-h light-dark cycle was in effect in the colony room. The light period began at $0700 \mathrm{~h}$ and ended at $2100 \mathrm{~h}$. Behavioral testing was conducted between 0800 and $1700 \mathrm{~h}$.

Animals were assigned at random to one of three groups. Ten rats received bilateral aspiration lesions of the hippocampal formation as well as part of the overlying dorsal neocortex. Ten additional rats received bilateral aspiration lesions of the same part of the neocortex that had been damaged in the rats given hippocampal lesions. These rats served as control preparations. Ten more rats served as unoperated controls.

A detailed description of the surgical procedure employed has been published (Isaacson \& Woodruff, 1976). Each rat in the groups that received lesions was anesthetized with an injection of Nembutal $(50 \mathrm{mg} / \mathrm{kg}$, ip). The scalp was shaved, incised at the midline, and retracted. Burr holes were made in the exposed skull overlapping the hippocampus and were expanded with rongeurs. The dura was slit and retracted. The neocortex was aspirated until a portion of the dorsal and lateral convexity of the hippocampus had been exposed. At this point, aspiration was stopped in the rats given only neocortical ablations. Aspiration was continued in the rats given hippocampal ablations until as much as possible of the hippocampus had been removed. Gelfoam was used to arrest bleeding, after which the scalp was closed with cotton sutures and 100,000 units of Flo-cillin were administered intramuscularly to combat possible postoperative infections. The rats were allowed 21 to 24 days for postoperative recovery before the experiment proceeded.

Operant conditioning. Each rat was given training in the operant paradigm before any operations were performed. Each rat was reduced to $85 \%$ of its free-feeding weight by means of a restricted feeding schedule allowing only $3 \mathrm{~g}$ of food daily. The rats were then trained to press a lever for food reinforcement using standard successive approximation techniques of shaping. Two BRS/LVE operant chambers (Model RTC-022) enclosed in soundattenuating environmental cubicles (BRS/LVE Model SEC-022) provided the experimental spaces for this experiment. Ventilation fans attached to the cubicles produced both air flow and continuous masking noise within the experimental space. Programming of schedule contingencies, as well as presentation of stimuli and reinforcement, was controlled by BRS/LVE Series 200 solidstate logic modules and electromechanical counters located in a room separated from the room in which the operant boxes were located. Reinforcement consisted of $45-\mathrm{mg}$ food pellets (P. J. Noyes Co., standard formula for rats). Experimental sessions were conducted Monday through Friday for every rat.

After each rat had been shaped to press the lever, it was trained 15 min a day for 5 days on an FR 1 schedule. Three cue lights were illuminated over the lever whenever an FR schedule was in effect during this period and throughout the remainder of the experiment. Upon completion of the 5-day exposure to the FR 1 schedule, the ratio was increased to 4 and the experimental session was extended to $30 \mathrm{~min}$. The FR 4 schedule was in effect for 5 days. This was followed by exposure to an FR 8 schedule for 10 days. an FR 16 schedule for 10 days, and an FR 32 schedule for 15 days.

The extinction (EXT) component was introduced 46 experimental sessions after the rats had first been exposed to the FR 1 schedule, and the schedule became a multiple schedule (MULT FR, EXT). The cue lights were turned off during the EXT periods.
During the first 3 days of training on the MULT FR, EXT schedule, the duration of each FR component was $8 \mathrm{~min}$ and the duration of each EXT component was $2 \mathrm{~min}$. The components alternated for a total session length of $30 \mathrm{~min}$. The EXT component was gradually extended and the FR component was shortened during the next nine experimental sessions until, in the final regimen, three 5-min FR 32 segments alternated with three 5-min EXT segments. An FR 32 component always began the session, and an EXT component always ended the session. The rats received 40 days of training under the final conditions of the MULT FR, EXT schedule before surgery was undertaken.

Upon completion of the recovery period, the body weight of each rat was again reduced to $85 \%$ of its free-feeding value by means of a restricted feeding schedule. The rats were then returned to the MULT FR 32, EXT schedule for 60 testing sessions. The preoperative training and this number of postoperative sessions were sufficient to produce stable performance on both schedules in all rats. Stability was assumed when the number of responses did not deviate more than $\pm 10 \%$ from the mean of the previous 3 days.

Drug injections were begun on Postoperative Testing Day 63 and were given at 7-calendar-day intervals for 5 consecutive weeks. The order of the types of injection was: $.9 \%$ saline, $1.6 \mathrm{mg} / \mathrm{kg}$, $.8 \mathrm{mg} / \mathrm{kg}, .4 \mathrm{mg} / \mathrm{kg}$, and $3.2 \mathrm{mg} / \mathrm{kg}$. The d-amphetamine sulfate was dissolved in saline. All injections were given ip $20 \mathrm{~min}$ before testing was begun. The dosages are in milligrams of the salt per kilogram of rat body weight. Operant testing was continued for 4 days following the final injection of d-amphetamine sulfate.

Histological analyses. Upon completion of behavioral analyses each rat that had received a lesion was killed by an overdose of Nembutal and was perfused through the left ventricle of the heart with $.9 \%$ saline, followed by $10 \%$ neutral buffered Formalin. The brains were postfixed in the same type of fixative until being transferred to a $15 \%$ sucrose-Formalin solution. After infiltration with the sucrose, frozen sections were cut at $30 \mu$ on a cryostat. Every sixth section was retained, slide-mounted, stained with thionine, and examined for extent of lesion.

\section{Results}

Histology. Examination of the hippocampal and neocortical lesions produced in the rats used in this experiment revealed that they were similar to those presented in reconstructions (Woodruff \& Isaacson, 1972) and photomicrographs (Woodruff, Means, \& Isaacson, 1973) published from this laboratory previously. The ablation of the hippocampus included virtually the complete dorsal (septal) and middle portions of the structure bilaterally in all 10 rats included in the hippocampal ablation group. Varying portions of the ventral (temporal) part of the hippocampus remained in these rats. Slight unilateral dorsal thalamic damage was present in four of the rats in this group. The thalamic damage was restricted to the lateral thalamic nucleus and could not be associated with any behavioral effects. Also, all rats with hippocampal ablations sustained damage to the neocortex and corpus callosum overlying the dorsolateral convexity of the hippocampus. The damage to the neocortex of the rats in the neocortical control group was comparable to that produced in the rats given hippocampal ablations. On each side of the brain the neocortical lesion began approximately $1 \mathrm{~mm}$ caudal to the septal tip of the hippocampus 
and extended caudally for approximately $2.5 \mathrm{~mm}$. Medially, the lesion began approximately $3 \mathrm{~mm}$ from the midline and extended laterally approximately $3 \mathrm{~mm}$. The corpus callosum was transected bilaterally in all rats given neocortical lesions, but damage to either the fimbria or hippocampus was observed in only one animal in Experiment 1 . The damage to the hippocampus was unilateral and had no apparent influence on the dependent variables measured in this experiment.

Operant responding. All of the statistical tests used to analyze the effects of the lesions and the drug on the MULT FR, EXT schedule are taken from Winer (1971). Two-way analyses of variance (ANOVA) with repeated measures on the treatment (drug dose) factor were applied to the number of responses emitted by the rats in the three groups for the total time that each schedule component was in effect for each experimental session during the 5 days preceding the injection. No significant difference was found for either the group or the days factor when the ANOVA was applied to the number of responses emitted during the FR condition, and there was no significant interaction effect. A significant group effect was found when the ANOVA was applied to the number of responses emitted during the preinjection EXT condition $[\mathrm{F}(2,27)=3.5, \mathrm{p}<.05]$. However, there were neither significant days nor interaction effects present. An a posteriori Newman-Keuls analysis indicated that the rats with hippocampal lesions responded significantly more often during EXT over the final 5 preinjection days than did the rats in either of the other two groups. Unoperated rats and rats with neocortical ablations did not differ on this measure.

Because the rats with hippocampal lesions responded significantly more often in the predrug condition than did either of the control groups during the EXT component, the data obtained on the days when drug or vehicle injections were given were subjected to a repeated measures analysis of variance and covariance. The number of responses emitted during EXT on the final preinjection day was used as the covariate. A similar analysis was conducted on the raw data for the FR component. Although the injections had been given in a mixed order, the data were placed in an ascending order of dose level from saline to the largest doses of amphetamine for analysis. The mean number of responses emitted during the EXT component for the final predrug day and each injection condition is presented in Figure 1. The mean for the number of responses emitted during the FR component under the same treatment conditions is presented in Figure 2.

For the EXT portion of the multiple schedule, the ANOVA revealed a significant group effect before the mean was adjusted for the covariate $[F(2,27)$ $=9.15, \mathrm{p}<.01]$. The probability that this effect

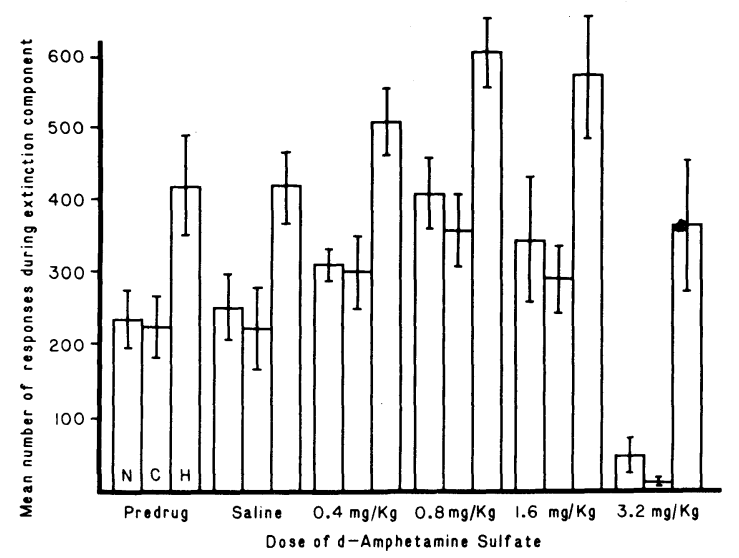

Figure 1. Mean number of responses emitted during the total time EXT components were in effect for the final day before injections were given and for each day an injection was given. The vertical lines represent the standard error of the mean. $N=$ unoperated control group, $\mathrm{C}=$ neocortically ablated control group, and $H=$ hippocampally ablated group.

occurred by chance was greater after adjustment by the covariate, but a putative level of significance was still attained $[\mathrm{F}(2,26)=4.52, \mathrm{p}<.03]$. The days (drug doses) effect was also significant $[\mathrm{F}(4,108)=$ 22.93, $\mathrm{p}<.001$ ]. No significant interaction effect was found. Analysis of the adjusted means with a Newman-Keuls test indicated that the group of rats with hippocampal lesions was significantly different from either of the other two groups, which did not differ from each other. Both the unadjusted and adjusted $F$ values were significant for the FR schedule $\left[F(2,27)=4.21, p<.05\right.$, and $F_{a d j}(2,26)=3.62$, $\mathrm{p}<.05]$. A significant days (drug dose) effect was found $[F(4,108)=59.32, p<.001]$, as was a significant interaction $[F(8,108)=2.88, p<.01]$. NewmanKeuls tests indicated that the rats with hippocampal lesions differed from both the unoperated and cortically ablated control groups. The control groups did not differ from each other.

In addition to the foregoing analysis of the data, the number of responses emitted during the total time spent in each component of the schedule by each rat on the day an injection was made was divided by the number of responses emitted during that component on the day immediately preceding the injection. The resulting number was multiplied by 100 to give the percent of the number of responses emitted on the predrug day. This manipulation circumvented the problem of differing baseline response levels for the different groups and also clearly indicated the direction of any change in number of responses induced by the drug injections. A two-way ANOVA with repeated measures on one factor (drug dose) was conducted for both EXT and FR. No significant group or interaction effect emerged for EXT, but the drug dose effect was significant $[F(4,108)=22.4$, $p<$ $.001]$. A significant group effect was found for FR 


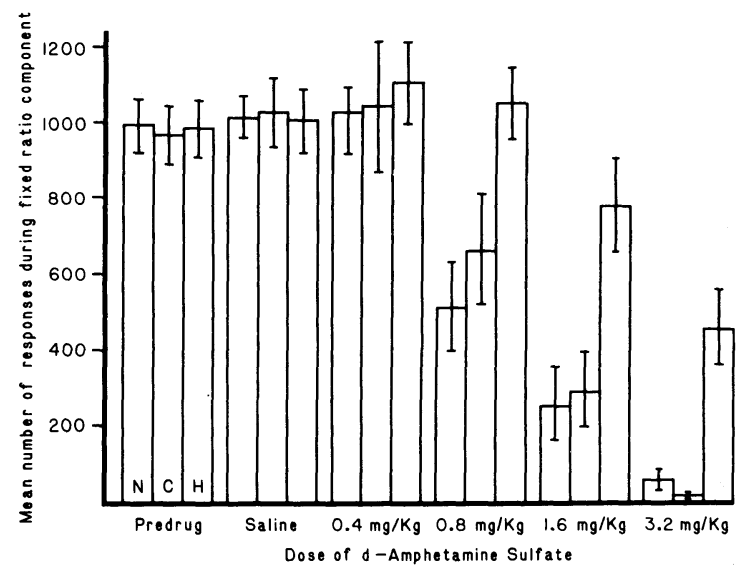

Figure 2. Mean number of responses emitted during the total time FR components were in effect for the final day before injections were given and for each day an injection was given. The vertical lines represent the standard error of the mean. Abbreviations are the same as in Figure 1.

$[F(2,27)=9.6, p<.001]$. The drug dose effect for FR was also significant $[\mathrm{F}(4,108)=68.5, \mathrm{p}<.0001]$, as was the interaction $[\mathrm{F}(8,108)=4.28, \mathrm{p}<.0001]$. Newman-Keuls analysis indicated that the rats with hippocampal lesions differed from the other two groups, which did not differ from each other.

\section{Discussion}

The rats in the group given hippocampal ablations emitted a larger number of responses during the FR portion of the multiple schedule after $.8,1.6$, and $3.2 \mathrm{mg} / \mathrm{kg}$ of d-amphetamine sulfate than did the rats in either Group C or Group N (Figure 2). The lesion effect is verified by the statistical analysis of the number of responses emitted after these injections and the percentage of predrug responses made after injection. Hippocampal ablation, therefore, significantly attenuates the reduction in responding on an FR schedule usually produced by amphetamine (Dews \& Wegner, 1977). This observation is consistent with the previous report by Woodruff and Isaacson (1977). However, the operant paradigm used in the present experiment was substantially different from that employed by Woodruff and Isaacson, and analysis of the data indicated that the attenuation of the drug effect by the hippocampal ablation was apparently greater at the higher than at the lower dose levels of the drug, as suggested by the statistically significant Group by Dose interaction.

The ability of the hippocampal lesion to attenuate the effect of amphetamine on operant responding with the paradigm employed in this experiment was limited to the response-decreasing properties of the drug. Injections of $.4, .8$, and $1.6 \mathrm{mg}$ of amphetamine for each kilogram of rat body weight increased responding in the control groups above noninjection and saline levels during the EXT portion of the schedule. If the hippocampal lesion simply attenuated the effect of amphetamine on operant responding generally, then the rats with hippocampal lesions should have responded less than did the control groups during EXT when under the influence of the drug. Indeed, a significant group effect was found in the covariate analysis of the response to the drug during EXT, but the hippocampally ablated group made significantly more, not fewer, responses than either of the control groups. This result could be interpreted as indicating that the hippocampal lesion actually augments the ability of amphetamine to increase the amount of responding during EXT. However, no significant group effect was found in the analysis of the percent of predrug responding during EXT. This finding suggests that, although a covariate analysis was performed for the number of responses, the apparent enhancement by the hippocampal lesion of the drug's effect may have been due to the elevated preinjection EXT response rate of the rats with hippocampal lesions.

The hippocampal lesion may not have augmented the effect of amphetamine on responding during EXT, but it certainly did not decrease it. This observation, as well as the significant alteration by hippocampal lesions of the effect of amphetamine on responding on an FR schedule, suggests that hippocampal lesions may specifically and directly attenuate the reduction in response rate usually produced by amphetamine when an animal is responding on a schedule that generates a relatively high predrug rate of response.

\section{EXPERIMENTS 2 AND 3}

The purpose of Experiment 2 was to determine whether hippocampal lesions altered the ability of amphetamine to produce anorexia. If the hippocampal ablation did alter the dose levels of amphetamine necessary to induce anorexia, then any change associated with the hippocampal lesion in the effect of amphetamine on operant responding might be attributable to lesion-induced changes in the effect of amphetamine on food consumption.

The purpose of Experiment 3 was to determine whether hippocampal lesions altered the dosage of amphetamine necessary to induce stereotyped behavior and to increase activity levels. If, for example, hippocampal lesions increased the amount of amphetamine necessary to produce either stereotypy or enhanced activity, these behaviors would not compete as quickly with operant responding as in control rats. Such a change in drug effect would explain the observation made by Woodruff and Isaacson (1977) that barpress rates on FR are higher after amphetamine injections for rats with hippocampal ablations than for controls. 


\section{Method}

Subjects and Surgical and histological procedures. Thirty rats were used in Experiment 2, while 24 rats were included in Experiment 3. The rats weighed between 297 and $352 \mathrm{~g}$ at the beginning of each experiment and were of the same sex and strain as those used in Experiment 1. Random selection was used to fill equal-sized groups in both experiments. The rats were unoperated or had either neocortical or neocortical and hippocampal aspiration ablations. The lesions were produced in the same manner as were the lesions in the rats in Experiment 1. The histological procedures were also the same.

Measurement of food consumption. Following the 21-day postoperative recovery period, the weight of each rat in Experiment 2 was reduced to $85 \%$ of its free-feeding value. The amount of food necessary to maintain the reduced body weight was recorded for each rat each day. Drug injections were begun 90 calendar days after food deprivation was begun. This was a preinjection time period comparable to that during which the rats in Experiment 1 were in the food deprived condition while being given postoperative training on the multiple schedule. The injections were given once every 7 days in the same order as in the first experiment: $.9 \%$ saline, $1.6, .8, .4$, and $3.2 \mathrm{mg} / \mathrm{kg}$ d-amphetamine sulfate.

Twenty minutes after receiving an injection, each rat was given the same amount of food it had been given the day preceding the injection. The amount of food eaten during the first $30 \mathrm{~min}$ after food was given was determined for the day 1 week before any injection and for each day an injection was made. This determination was made by giving each rat the daily quantity of food it required to maintain itself at $85 \%$ of its free-feeding weight. The cages were the "shoebox" type with solid bottoms and sides. When $\mathbf{3 0}$ min had elapsed, as much of the remaining food as possible was quickly removed from the cage and weighed. Some small crumbs and food powder were probably not collected, but this was a minute amount and was taken to be constant across subjects. After the food had been weighed, it was returned to the rats.

Measurement of activity and stereotypy. Because Experiment 3 was intended to provide data that were as relevant as possible to those obtained in Experiment 1, the body weights of the rats used in this experiment were reduced to $85 \%$ of their ad-lib value and were maintained at this level for 90 days. During this 90 -day period, each rat was placed in the operant boxes used in Experiment 1 for 30 min each day from Monday through Friday. Following this period, the same injections were given in the same order as in the first two experiments. Injections were given on Wednesdays, 1 week separated each injection, and the uninjected rats were placed in the boxes for 30 min on Monday, Tuesday, Thursday, and Friday. Twenty minutes following injection, each rat was placed in the operant box, and activity and stereotypy were assessed. Data concerning activity and stereotypy were collected on Wednesday, 1 week before any injections were given and after each injection was given. An activity measure was obtained by counting the number of times in 30 min the rat crossed the center of the operant box from front to back or back to front with all four feet. Stereotypy was assessed simultaneously by two independent observers using a scale based upon that described by Creese and Iverson (1973). Beginning with the first minute the rat was in the box, stereotypy ratings were made for $1 \mathrm{~min}$ every $9 \mathrm{~min}$. The scale was applied as follows: 0 , motionless or sleeping; 1 , active, exhibiting forward motion not along a fixed path; 2 , bursts of stereotyped rearing or sniffing mixed with forward motions along a straight, fixed path; 4 , stereotyped sniffing or rearing in one location; 5, sniffing or rearing in one location with some gnawing of the bars of the box floor and licking; 6 , continued gnawing and licking.

\section{Results}

Histology. The lesions produced in the rats with hippocampal or neocortical damage were equivalent to those observed in similar preparations in Experiment 1 . Two of the rats given hippocampal lesions and used in Experiment 2 had suffered unilateral damage to the lateral thalamic nucleus as had two of the hippocampectomized rats included in Experiment 3. Two of the rats included in the neocortically damaged control group in Experiment 2 and one neocortically damaged control rat in Experiment 3 had sustained slight unilateral hippocampal damage.

Experiment 2: Food consumption. The dependent variable for statistical analysis of the effects of the lesions and amphetamine on food consumption was obtained by dividing the amount of food eaten in 30 min by the amount of food given and multiplying the resulting quotient by 100 to obtain the percent of food given that was eaten. This was done for the noninjection day 1 calendar week before the saline injection and for the day each injection was given. A two-way ANOVA with a repeated measure on the treatment (drug dose) effect was conducted on these numbers. The mean percentage of food given that was eaten for the preinjection condition and the five injection conditions is presented for each group in Table 1. The statistical analysis indicated that there was neither a significant group nor a significant interaction effect. The treatment effect achieved a high level of significance $[F(5,135)=162.3, p<.0001]$.

Experiment 3: Activity and stereotypy. The mean number of times the center of the operant box was crossed by members of each group during each of the 6 days that data were collected is presented, together with the standard error of the mean, in Table 2. A two-way ANOVA and covariate analysis with a repeated measure on the treatment effect was conducted on these activity data. The data collected 1 week before the injection series was begun served as the covariate. The ANOVA for the unadjusted means rendered a significant group effect $[F(2,21)=$ $14.7, \mathrm{p}<.01$ ], but when the means were adjusted for the covariate, the group effect was no longer significant $\left[F_{a d j}(2,20)=.072, p>.05\right]$. This indicates that differences in predrug levels of activity accounted for the significant group effect found by the ANOVA. A Newman-Keuls analysis of the unadjusted means indicated that the rats with hippocampal ablations were significantly different from the two control groups, which did not differ from each other. The treatment effect was significant $[F(4,84)=73.7$, $\mathrm{p}<.01]$. The interaction was not statistically significant.

Because the numbers assigned as scores for the stereotypy rating scale are discontinuous and only artificially related to the observed behaviors, parametric analysis could not be done for the stereotypy data. Therefore, nonparametric tests were applied (Siegel, 1956). The data are presented in Table 3 as medians and ranges. A Spearman rank correlation coefficient was computed for the data gathered by the two observers and the correlation was high $\left(r_{s}=\right.$ $.91)$. 
Table 1

Mean and Standard Error of the Mean Percent of Daily Food Ration Eaten in 30 Min for Each Group

\begin{tabular}{|c|c|c|c|c|c|c|c|c|c|c|c|c|}
\hline \multirow[b]{2}{*}{ Lesion } & \multicolumn{2}{|c|}{ Preinjection } & \multicolumn{2}{|c|}{ Saline } & \multicolumn{2}{|c|}{$.4 \mathrm{mg} / \mathrm{kg}$} & \multicolumn{2}{|c|}{$.8 \mathrm{mg} / \mathrm{kg}$} & \multicolumn{2}{|c|}{$1.6 \mathrm{mg} / \mathrm{kg}$} & \multicolumn{2}{|c|}{$3.2 \mathrm{mg} / \mathrm{kg}$} \\
\hline & Mean & SE & Mean & $\mathrm{SE}$ & Mean & SE & Mean & SE & Mean & SE & Mean & SE \\
\hline Hippocampal & 51 & 3.2 & 51 & 3.0 & 43 & 3.0 & 49 & 1.7 & 7 & 3.4 & 3 & 2.0 \\
\hline Neocortical & 48 & 3.2 & 50 & 4.3 & 39 & 4.0 & 44 & 4.8 & 4 & 1.8 & 4 & 2.9 \\
\hline Unoperated & 46 & 2.8 & 50 & 3.1 & 41 & 3.7 & 40 & 4.3 & 5 & 3.1 & 2 & 1.3 \\
\hline
\end{tabular}

Table 2

Mean and Standard Error of the Mean Number of Centerline Crossings in the Operant Boxes for Each Group

\begin{tabular}{|c|c|c|c|c|c|c|c|c|c|c|c|c|}
\hline \multirow[b]{2}{*}{ Lesion } & \multicolumn{2}{|c|}{ Preinjection } & \multicolumn{2}{|c|}{ Saline } & \multicolumn{2}{|c|}{$.4 \mathrm{mg} / \mathrm{kg}$} & \multicolumn{2}{|c|}{$.8 \mathrm{mg} / \mathrm{kg}$} & \multicolumn{2}{|c|}{$1.6 \mathrm{mg} / \mathrm{kg}$} & \multicolumn{2}{|c|}{$3.2 \mathrm{mg} / \mathrm{kg}$} \\
\hline & Mean & SE & Mean & $\mathrm{SE}$ & Mean & $\mathrm{SE}$ & Mean & $\mathrm{SE}$ & Mean & $\mathrm{SE}$ & Mean & SE \\
\hline $\begin{array}{l}\text { Hippocampal } \\
\text { Neocortical } \\
\text { Unoperated }\end{array}$ & $\begin{array}{r}84.6 \\
80.0 \\
145.3\end{array}$ & $\begin{array}{r}4.3 \\
5.3 \\
11.4\end{array}$ & $\begin{array}{r}81.4 \\
80.6 \\
142.5\end{array}$ & $\begin{array}{r}5.3 \\
6.4 \\
10.8\end{array}$ & $\begin{array}{r}93.9 \\
85.8 \\
154.6\end{array}$ & $\begin{array}{r}8.8 \\
7.8 \\
14.2\end{array}$ & $\begin{array}{l}149.4 \\
137.1 \\
180.0\end{array}$ & $\begin{array}{r}9.8 \\
10.0 \\
12.9\end{array}$ & $\begin{array}{l}195.1 \\
211.5 \\
219.1\end{array}$ & $\begin{array}{r}5.7 \\
13.9 \\
10.7\end{array}$ & $\begin{array}{r}74.9 \\
77.3 \\
182.9\end{array}$ & $\begin{array}{r}10.7 \\
8.5 \\
7.0\end{array}$ \\
\hline
\end{tabular}

Table 3

Median and Range for Stereotypy Ratings for Each Sample Time at Each Treatment Level

\begin{tabular}{|c|c|c|c|c|c|c|c|c|c|c|c|c|}
\hline \multirow{2}{*}{$\begin{array}{l}\text { Sample Time } \\
\text { (in Minutes) }\end{array}$} & \multicolumn{2}{|c|}{ Preinjection } & \multicolumn{2}{|c|}{ Saline } & \multicolumn{2}{|c|}{$.4 \mathrm{mg} / \mathrm{kg}$} & \multicolumn{2}{|c|}{$.8 \mathrm{mg} / \mathrm{kg}$} & \multicolumn{2}{|c|}{$1.6 \mathrm{mg} / \mathrm{kg}$} & \multicolumn{2}{|c|}{$3.2 \mathrm{mg} / \mathrm{kg}$} \\
\hline & Median & Range & Median & Range & Median & Range & Median & Range & Median & Range & Median & Range \\
\hline \multicolumn{13}{|c|}{ Hippocampal Lesions } \\
\hline $0-1$ & 1 & $0-2$ & 1 & $0-2$ & 1 & $0-2$ & 2.0 & $1-3$ & 3 & $2-4$ & 4.0 & $3-5$ \\
\hline $9-10$ & 1 & $1-2$ & 2 & $0-3$ & 1 & $1-2$ & 2.0 & $1-3$ & 3 & $2-5$ & 4.0 & $3-4$ \\
\hline $19-20$ & 1 & $0-2$ & 1 & $1-2$ & 1 & $0-2$ & 2.0 & $1-3$ & 3 & $2-4$ & 3.5 & $3-5$ \\
\hline $29-30$ & 1 & $0-2$ & 1 & $0-3$ & 1 & $0-2$ & 2.0 & $1-2$ & 3 & $2-4$ & 3.5 & $3-5$ \\
\hline \multicolumn{13}{|c|}{ Neocortical Lesions } \\
\hline $0-1$ & 2 & $0-3$ & 1 & $1-2$ & 1 & $1-2$ & 2.0 & $1-3$ & 3 & $2-4$ & 3.0 & $3-6$ \\
\hline $9-10$ & 1 & $1-2$ & 1 & $0-1$ & 1 & $0-2$ & 2.0 & $1-3$ & 3 & $2-5$ & 4.0 & $3-5$ \\
\hline $19-20$ & 1 & $0-2$ & 1 & $1-2$ & 1 & $1-2$ & 2.0 & $1-3$ & 3 & $2-5$ & 4.0 & $3-4$ \\
\hline $29-30$ & 1 & $1-2$ & 1 & $1-2$ & 1 & $0-2$ & 1.5 & $1-3$ & 3 & $1-4$ & 3.0 & $3-5$ \\
\hline \multicolumn{13}{|c|}{ Unoperated } \\
\hline $0-1$ & 1 & $0-1$ & 1 & $0-1$ & 1 & $0-2$ & 2.0 & $1-3$ & 3 & $2-3$ & 4.0 & $3-5$ \\
\hline $9-10$ & 1 & $0-1$ & 2 & $1-3$ & 1 & $1-2$ & 2.0 & $1-3$ & 3 & $2-4$ & 4.0 & $3-6$ \\
\hline $19-20$ & 1 & $0-2$ & 1 & $0-1$ & 1 & $1-2$ & 2.0 & $1-3$ & 3 & $2-4$ & 3.0 & $3-5$ \\
\hline $29-30$ & 1 & $0-1$ & 1 & $0-2$ & 1 & $1-2$ & 1.5 & $1-0$ & 3 & $2-4$ & 4.0 & $3-4$ \\
\hline
\end{tabular}

The data from both observers were analyzed, and the results were the same. Therefore, for the sake of brevity, one set of results was chosen at random for presentation. Stereotypy was rated four times during each 30-min data collection period. A Friedman twoway ANOVA for related samples was conducted for each 30-min period for each group to determine whether or not the stereotypy ratings changed within a session. No statistically significant changes were found. Because no apparent change in severity of stereotypy was found within any session, only the stereotypy rating done 19 to 20 min after the session began was used for further statistical analysis. However, the median and range from each of the four sample periods within each data collection session are presented in Table 3.

The stereotypy scores from 19 to 20 min after the beginning of the session were compared across groups for each treatment condition using Kruskal-Wallis one-way ANOVAs for independent samples. The Kruskal-Wallis analyses were applied to determine whether a group difference existed for any of the days during which stereotypy ratings were made. None of the Kruskal-Wallis tests yielded significant results.

Finally, Friedman two-way ANOVAs were applied to the same data from each group to determine whether a drug dose effect was present. The results of these tests were very significant (unoperated controls, $\chi \mathrm{r}^{2}=65.6$; cortically ablated controls, $\chi \mathrm{r}^{2}=62.1$; hippocampally ablated rats, $\chi \mathrm{r}^{2}=63.8 ; \mathrm{p}<.001$ and $\mathrm{df}=4$ for all cases).

\section{Discussion}

As can be seen in Table 1, anorexia was produced by injections of 1.6 and $3.2 \mathrm{mg} / \mathrm{kg}$ d-amphetamine, but there were no significant group differences in this response. In addition, neither cortical nor hippocampal lesions altered the threshold dose or severity of amphetamine-induced stereotypy (Table 3).

The data collected for activity within the operant chambers (Table 2) were not as unequivocal as were 
those for anorexia and stereotypy. The rats with hippocampal lesions were more active before the drug was given, and this predrug difference in activity was apparently responsible for the difference in response to the drug. When predrug activity scores were included as covariates, there were no longer any significant overall group effects after drug injections. The finding that hippocampal lesions increase activity is in agreement with previous reports (Campbell et al., 1971; Kimble, 1963; Woodruff \& Bailey, 1979). However, Campbell et al. (1971) found that hippocampal ablations in rats facilitated the activityenhancing effect of amphetamine. This observation was apparently not replicated in the present study. Several methodological differences exist between the two studies, including different types of testing apparatus and strain of rat. In addition, two major differences in treatment of the rats exist between the two experiments. The postoperative recovery time was 5 weeks in the experiment done by Campbell et al. but $13 \frac{1 / 2}{2}$ weeks in the present experiment. It is possible that hippocampal lesion-induced changes, such as axonal sprouting in the septal area (Moore, Björklund, $\&$ Stenevi, 1971), might be more pronounced after the longer recovery period and that such changes accounted for the different results, but this seems unlikely. Although such changes not only are demonstrable using anatomical techniques (Moore et al., 1971; Raisman, 1969) but also appear to have consequences for behavior (Baisden \& Woodruff, 1980; Kimble, 1976), they are essentially complete after about 3 weeks.

The second difference in treatment of the rats in the present study, as compared with that of Campbell et al. (1971), may better account for the discrepancy in findings. The rats used in the present experiment were food-deprived for over 13 weeks before the drug injections were begun. Food deprivation enhances activity levels in rats, and Campbell et al. demonstrated that, in addition to facilitating amphetamine-induced activity increases, hippocampal lesions also augment food-deprivation-induced activity increases. Campbell et al. did not combine both food deprivation and amphetamine treatment, as was done in this experiment. It may be that the maximal potential of the hippocampal lesion to facilitate activity increase produced by changes in another variable (e.g., food deprivation) had been achieved in Experiment 3. For this reason, amphetamineinduced activity increase may not have interacted with the lesion effect, as it did in the experiment by Campbell et al.

\section{GENERAL DISCUSSION}

It is evident that lesion-induced changes in alterations produced by amphetamine in locomotor activity, stereotyped behavior, and food consumption do not account for the reduction produced by hippo- campal ablation in the effectiveness of amphetamine in depressing response rate on the FR schedule. Taken together, the data from the three experiments conducted in this study suggest that the hippocampal lesion had a specific effect on the ability of amphetamine to reduce response rate on the FR schedule.

These data suggest the hypothesis that the hippocampus is one anatomical area involved in the "ratedependent" effect of d-amphetamine first described by Dews (Dews, 1958, 1972; Dews \& Wenger, 1977). The possible physical bases for the effects of d-amphetamine on operant responding have been investigated using biochemical methodology, and, although some general relationships have been demonstrated between central noradrenergic activity and responding on operant schedules (Albert, Emmett-Oglesby, \& Seiden, 1977; Lewy \& Seiden, 1972; Seiden \& Dykstra, 1977; Sparber \& Tilson, 1972), there is no agreement (Cole \& Gay, 1974) as to the identity of either the anatomical structures or neurochemical systems that underlie the ability of predrug response rates to determine, at least in part, whether amphetamine will increase or decrease responding. The results obtained in this study and in the experiment done by Woodruff and Isaacson (1977) indicate that the hippocampus is one of the structures that make up the anatomical substrate that produces the behavioral effect known as "rate dependency." Moreover, the hippocampus is involved in the rate-reducing, but not the rateincreasing, portion of this behavioral phenomenon. This observation suggests that the physical basis of the "rate-dependency" phenomenon does not consist of a unitary mechanism responsible for both rate increases and rate decreases.

It is comparatively simple to interpret the data gathered in these experiments as indicating that the hippocampus is one structure involved in the ratedecreasing effects of amphetamine. It is more difficult to place these data within a general theoretical context concerning hippocampal function. This difficulty exists not only because of the problems inherent in interpretation of the meaning of lesionbehavior interactions, but also because the precise meaning of the rate-dependency phenomenon itself is not clear. However, Dews and Wenger (1977) have proposed that rate-dependent changes in operant responding are not necessarily produced only by drugs, but may be caused by introduction of any novel stimulus into the environment of an animal performing on an operant schedule. Ksir (1976) had earlier made a similar point and had presented data that suggested that rate dependency was a special instance of state dependency. That is, when the internal (or the external) stimulus condition of an animal suddenly changes, and the animal is performing on an operant task, one of the variables that would predict the effect of the stimulus change on operant responding would be the prechange response rate. If this theoretical context is accepted for the rate-dependency 
phenomenon, then the results of the present study could be interpreted to indicate that the intact hippocampus is involved in monitoring changes in both the internal and external sensory environment, with the consequence that ongoing behavior, especially if emitted at a high rate, is slowed in order that the behavior may be changed, if necessary, to meet changes in the environment. This view of hippocampal function is compatible with that of Douglas (1967) and emphasizes the role of the hippocampus as an interpreter of the importance of sensory input.

\section{REFERENCES}

AdLe R, M. W. Changes in sensitivity to amphetamine in rats with chronic brain lesions. Journal of Pharmacology and Experimental Therapeutics, 1961, 134, 214-221.

Albert, L. H., Emmett-Oglesby, M., \& Seiden, L. S. Effects of schedules of reinforcement on brain catecholamine metabolism in the rat. Pharmacology, Biochemistry and Behavior, 1977, 6, 481-486.

Baisden, R. H., \& Woodruff, M. L. Behavioral effects of hippocampal lesions in rats with prior intraseptal injection of 6hydroxydopamine. Physiological Psychology, 1980, 8, 33-39.

Campbell, B. A., Ballantine, P., \& Lynch, G. Hippocampal control of behavioral arousal: Duration of lesion effects and possible interactions with recovery after frontal cortical damage. Experimental Neurology, 1971, 33, 159-170.

Cole, S. O., \& GraY, P. E. Brain mechanisms underlying the effects of amphetamine on feeding and nonfeeding behaviors: Dissociation and overlap. Physiological Psychology, 1974, 2, 80-88.

Creese, I., \& Iversen, S. D. Blockage of amphetamine induced motor stimulation and stereotypy in the adult rat following neonatal treatment with 6-hydroxydopamine. Brain Research, 1973, 55, 369-382.

DEws, P. B. Analysis of the effects of pharmacological agents in behavioral terms. Federation Proceedings, 1958, 17, 1024-1030.

DEws, P. B. Assessing the effect of drugs. In R. D. Meyers (Ed.), Methods in psychobiology (Vol. 2). New York: Academic Press, 1972.

Dews, P. B., \& Wenger, G. R. Rate-dependency of the behavioral effects of amphetamine. In T. Thompson \& P. B. Dews (Eds.), Advances in behavioral pharmacology (Vol. 1). New York: Academic Press, 1977.

Douglas, R. J. The hippocampus and behavior. Psychological Bulletin, 1967, 67, 416-422.

Ferster, C. B., \& Skinner, B. F. Schedules of reinforcement. New York: Appleton-Century-Crofts, 1957.

GLICK, S. D. Changes in amphetamine sensitivity following frontal cortical damage in rats and mice. European Journal of Pharmacology, 1972, 20, 351-356.

Glick, S. D., \& Marsanico, R. G. Shifting of the d-amphetamine dose-response curve in rats with frontal cortical ablations. Psychopharmacologia, 1974, 36, 109-115.

IsAACsON, R. L., \& WoODRUFF, M. L. Spontaneous alternation and passive avoidance behavior in rats after hippocampal lesions. In B. Hart (Ed.), Experimental psychobiology: A laboratory manual. San Francisco: Freeman, 1976.

Iversen, S. D. 6-hydroxydopamine: A chemical lesion technique for studying the role of amine neurotransmitters in behavior. In F. O. Schmitt \& F. G. Wordon (Eds.), The neurosciences: Third study program. Cambridge, Mass: M.I.T. Press, 1974.

Kimble, D. P. The effects of bilateral hippocampal lesions in rats. Journal of Comparative and Physiological Psychology, 1963, 56, 273-283.

Kimble, D. P. Changes in behavior of hippocampal-lesioned rats across a 6-week postoperative period. Physiological Psychology, 1976, 4, 289-293.

KsIR, C. Rate dependent drug effects: Possible state dependency. Pharmacology, Biochemistry and Behavior, 1976, 4, 165-168.

LEWY, A., \& Seiden, L. S. Operant behavior changes norepinephrine metabolism in rat brain. Science, 1972, 175, 454-456.

Lynch, G. S., Ballantine, P., \& Campbell, B. A. Potentiation of behavioral arousal after cortical damage and subsequent recovery. Experimental Neurology, 1969, 23, 195-206.

MILlE R, M. H. Behavioral effects of amphetamine in a group of rhesus monkeys with lesions of dorsolateral frontal cortex. Psychopharmacology, 1976, 47, 71-74.

Moore, R. Y., Buörklund, A., \& Stenevi, U. Plastic changes in the adrenergic innervation of the rat septal area in response to denervation. Brain Research, 1971, 33, 13-35.

Neil, D. B., Boggan, W. O., \& Grossman, S. P. Behavioral effects of amphetamine in rats with lesions of the corpus striatum. Journal of Comparative and Physiological Psychology, $1974,86,1019-1030$.

Raisman, G. Neuronal plasticity in the septal nuclei of the adult rat. Brain Research, 1969, 14, 25-48.

Seiden, L. S., \& Dykstra, L. A. Psychopharmacology: A biochemical and behavioral approach. New York: Van Nostrand Reinhold, 1977.

SIEGEL, S. Nonparametric statistics for the behavioral sciences. New York: McGraw-Hill, 1956.

Sparber, S. B., \& Tilson, H. A. Schedule controlled and drug induced release of norepinephrine-7- ${ }^{3} \mathrm{H}$ into the lateral ventricle of rats. Neuropharmacology, 1972, 11, 453-464.

WINER, B. J. Statistical principles in experimental design (2nd ed.). New York: McGraw-Hill, 1971.

WoodrufF, M. L., \& BAILEy, S. D. Hippocampal lesions and immobility responses in the rat. Physiological Psychology, 1979, 7, 254-258

Woodruff, M. L., \& Isaacson, R. L. Discrimination learning in animals with lesions of hippocampus. Behavioral Biology, $1972,7,489-501$.

Woodruff, M. L., \& Isaacson, R. L. Attenuation of the ratedecreasing effects of amphetamine on fixed-ratio responding in rats by hippocampal lesions. Behavioral Biology, 1977, 20, 493-499.

Woodruff, M. L., Means, L. W., \& Isaacson, R. L. Deficient go, no-go brightness discrimination in rats following hippocampal lesions. Physiological Psychology, 1973, 1, 85-88.

(Received for publication February 23, 1981. accepted May 6, 1981.) 